\title{
Retention of platelets by glass bead filters
}

\author{
W. R. PITNEY ${ }^{1}$ AND MARY POTTER \\ From the School of Pathology, University of New South Wales, Sydney, Australia
}

SYNOPSIS Whole blood was passed through glass bead filters and the retention of platelets studied under various experimental conditions. Platelet retention was similar over a wide range of blood flow rates; however, it was decreased at fast rates of flow. Platelet retention was not influenced by the haematocrit value of the blood over a wide range. Retention in filters containing siliconized beads was similar to that in filters with untreated beads. Platelet retention was inhibited by the addition of citrate or adenosine to the blood before passage through the filter and was also less when the blood was cooled. Heparin and phenylindandione therapy did not affect the results.

There was a wide range of results of platelet retention tests with normal blood samples and considerable variability between the results of duplicate samples from the same donor. Repeated testing of normal donors over a three-month period gave results which varied widely within the normal range. Twenty-two of 40 uraemic blood samples showed decreased platelet retention. The mechanism of platelet retention from whole blood by glass bead filters is not clear but may be related to platelet aggregation induced by adenosine diphosphate or other aggregating agents.

The recent introduction of tests to measure various aspects of platelet function reflects the increasing awareness that abnormalities of platelet adhesion and aggregation may be important both in thrombotic states and in certain bleeding disorders. One such test is the measurement of platelet retention when citrated (Hellem, 1960) or native whole blood (O'Brien, 1961; Salzman, 1963a) is passed through a filter of glass beads. It is not clear what aspects of platelet function are involved in tests of this type, but it is possible that both platelet adhesion to the glass beads and the production of platelet aggregates cause retention of platelets by the filter.

Salzman (1963a) withdrew venous blood directly through a glass bead filter interposed between the needle and a vacutainer. The difference between a venous platelet count obtained from a second venepuncture and the platelet count of the blood which has passed through the filter was a measure of platelet 'adhesiveness'. Decreased 'adhesiveness' occurs in von Willebrand's disease, thrombasthenia, uraemia, and during extracorporeal circulation (Salzman, 1963 a and b; Salzman and Neri, 1966). The decreased platelet 'adhesiveness' in von Willebrand's disease has been confirmed by Strauss and Bloom (1965). It is obvious, therefore, that this

1Present address: Department of Haematology, Royal Postgraduate Medical School of London.

Received for publication 9 March 1967. test has important clinical applications, even though the precise mechanism of platelet retention is not known.

This paper reports an investigation of the retention of platelets by glass bead filters under various experimental conditions to assess some of the factors which may cause variability in this test. Since we wished to carry out manipulations on the blood in some instances, venous blood was collected into a syringe and then passed through the filter rather than withdrawn directly through the filter into a vacutainer.

\section{METHODS}

DESCRIPTION OF THE TEST Venous blood was collected with minimal stasis and absence of frothing through a 19 SWG needle into well-siliconized or plastic syringes. The needle was removed and the syringe immediately fitted to a plastic tube containing glass beads. Constant pressure was exerted on the plunger of the syringe so that $2 \mathrm{ml}$. of blood issued from the distal end of the plastic tube in 30 seconds. This blood was collected into a small bottle containing $4 \mathrm{mg}$. dipotassium sequestrene. The remaining blood in the syringe was placed in a second bottle also containing sequestrene. Platelet counts were performed on both blood samples. The decrease in platelet numbers, expressed as a percentage of the platelet count of the unfiltered sample, indicated the percentage retention of platelets in the glass bead filter.

The filter was constructed as follows: two discs each of diameter $3.2 \mathrm{~mm}$. were cut from stainless steel mesh 
(200 size, aperture $0.075 \mathrm{~mm}$.). One disc was glued onto the narrow end of a stainless steel luer-lok rubber connector and the other to the narrow end of a portex connector (M. 702 Boots). The discs were then treated with silicone (Silcote SF 114). A $10 \mathrm{~cm}$. length of polyvinyl tubing (internal diameter, $3.2 \mathrm{~mm}$.) was filled with glass beads (Superbrite type 071-5895, size 0.0215 in. to 0.0066 in. Minnesota Mining and Manufacturing Co.) and sealed at both ends with the connectors. After use, the tubing and connectors were reassembled after flushing with distilled water and drying at $37^{\circ} \mathrm{C}$. New glass beads were used for each test.

PLATELET COUNTS Platelet counts were performed by phase contrast microscopy on a 1 in 100 dilution of blood in formol citrate solution. The platelets were counted in one square $\mathrm{mm}$. area of the counting chamber.

ADDITION OF VARIOUS SUBSTANCES In several instances parallel observations on platelet retention were made with native blood and blood diluted with various substances. The procedure involved a two-syringe technique, the needle remaining in the vein. Blood was drawn into one syringe and platelet retention recorded in the usual manner. A further known volume of blood was then drawn into the second syringe containing a known volume of the test material. Mixing was carried out in the syringe after which platelet retention was measured through a second filter unit.

In experiments designed to study the effect of temperature on platelet retention, the glass bead filter unit was placed in a length of glass tubing closed at either end with a perforated rubber bung. The outer glass tubing was partially filled with water and held for one hour at $-20^{\circ} \mathrm{C}$. and then at room temperature until the ice began to melt. Parallel observations were made using both the cold filter unit and one at room temperature. Observations with a thermistor in the tubing showed that blood was cooled to an average of $27^{\circ} \mathrm{C}$. on contact with the glass beads.

In some experiments, the glass beads were siliconized before incorporation into filter units, the beads being soaked with frequent agitation in a beaker containing a $1 \%$ solution of Silcote SF. 114 in distilled water. They were then blotted on filter paper and dried for 30 minutes at $250^{\circ} \mathrm{F}$. in a hot air oven.

Tests were carried out on normal individuals, on patients receiving anticoagulant therapy with either heparin or phenylindanedione (Dindevan), and on patients with anaemia and polycythaemia. Tests were also made on patients with uraemia as part of a wider study of platelet dysfunction in that disorder.

In some experiments, native whole blood which had passed through the filter was collected into a polystyrene centrifuge tube and centrifuged at 16,000 r.p.m. for 10 minutes in a refrigerated centrifuge at $4^{\circ} \mathrm{C}$. Immediately thereafter, $1 \mathrm{ml}$. native plasma was mixed with an equal volume of $0.6 \mathrm{M}$ perchloric acid to precipitate the proteins. The supernatant was neutralized with one half volume of triethaneolamine-potassium carbonate buffer and tested for platelet clumping activity, using the change in optical density of citrated, platelet-rich normal plasma as an indicator system (Born, 1962). As a control, adenosine diphosphate was added to native whole blood before passage through the filter and native plasma prepared and treated with perchloric acid as described above. The amount of A.D.P. added was such that the concentration in the neutralized perchloric acid extract should have been $2 \mu \mathrm{g} . / \mathrm{ml}$. provided that no degradation had occurred.

\section{RESULTS}

NORMAL SUBJECTS The percentage of platelets retained by the glass bead filter was determined on blood samples from 56 normal subjects, mostly laboratory workers of both sexes aged 18-44 years. The values ranged from $30.2 \%$ to $91.9 \%$, although only three values fell below $40 \%$ and only one value exceeded $90 \%$. The mean percentage platelet retention was $65.2 \%$. The results for the 56 cases are recorded in Figure 1.

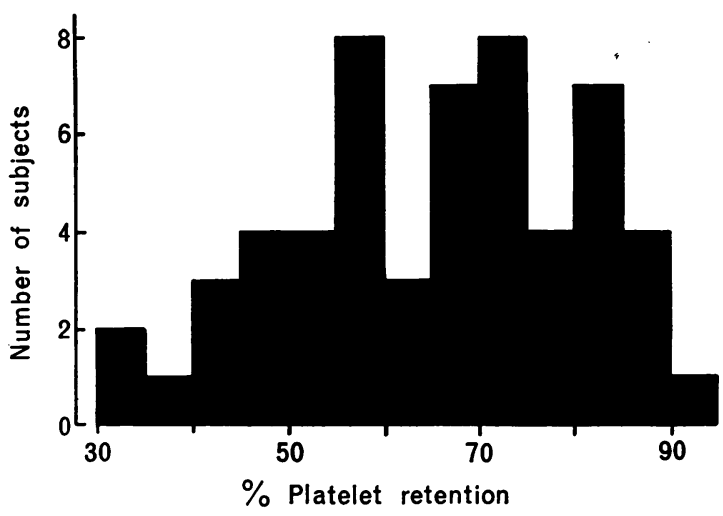

FIG. 1. Results of platelet retention test in 56 normal subjects.

REPLICABILITY OF THE TEST In eight experiments on normal subjects and 34 on patients with various disorders, duplicate blood samples from the same syringe were passed through separate filters at a constant flow rate so that $2 \mathrm{ml}$. blood issued from each filter in 30 seconds. The duplicate determinations for all 42 individuals are recorded in Figure 2. The considerable variation presumably reflects platelet count errors and differences in the characters of filter units. The results were consistent in 36 of the 42 duplicate tests, 30 duplicate results both exceeding $30 \%$, and six both being less than $30 \%$. In one case, platelet retention was normal in the first filter but low in the second; and in five instances, the position was reversed. 


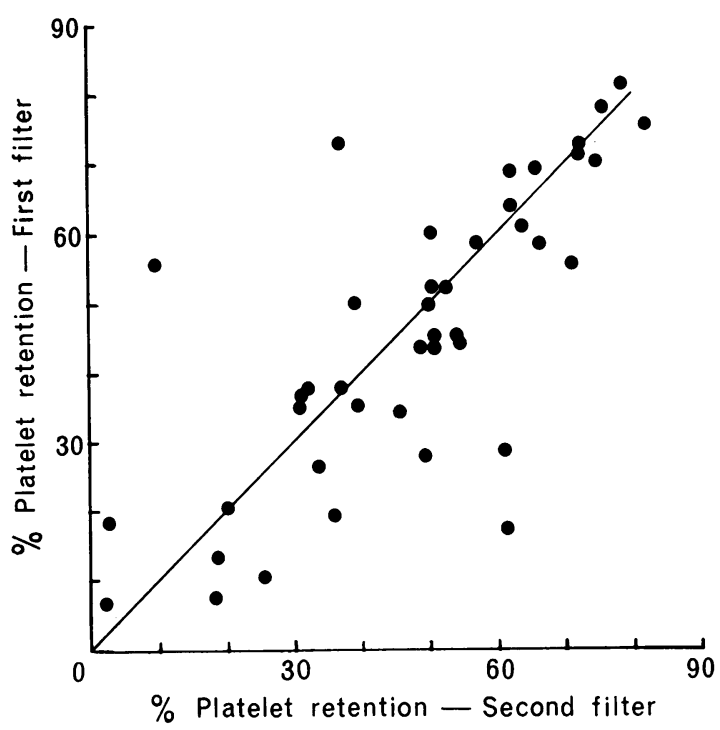

FIG. 2. Results of duplicate tests from the same blood sample in 42 individuals.

REPRODUCIBILITY OF THE TEST In 13 normal subjects the test was repeated once or twice over a period of three months. The results (Table I) vary widely within the normal range. When the test was repeated, no result fell below $30 \%$ but the variation was such that it was not possible to ascribe a degree of normality to any subject. Thus a 'high' normal on one test could be a 'low' on repeat testing.

\section{TABLE I}

REPRODUCIBILITY OF THE PLATELET RETENTION TEST IN NORMAL SUBJECTS

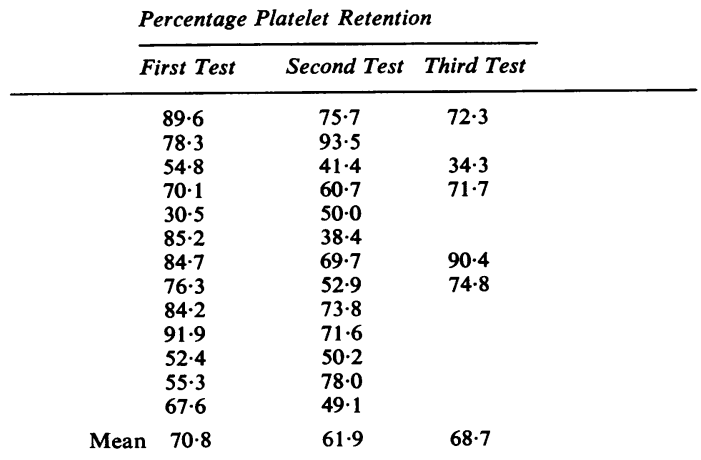

VARIATION IN BLOOD FLOW RATE In five tests on normal subjects, duplicate blood samples from the same syringes were passed through separate filters at rates varying from 1.0 to $2.8 \mathrm{ml}$. in 30 seconds.
The results are recorded in Table II. In three tests, fewer platelets were retained in the filter at the higher $\stackrel{9}{?}$ flow rate, while in one the effect was reversed. The differences were of the same order as those in experiments designed to test replicability. All results fell in the normal range so that it appears likely that small variations in the rate of blood flow within the limits described have little effect on platelet retention.

TABLE II

PLATELET RETENTION AT VARYING RATES OF BLOOD FLOW THROUGH THE FILTERS

\begin{tabular}{|c|c|c|}
\hline Experiment No. & $\begin{array}{l}\text { Flow Rate } \\
\text { (ml./30 sec) }\end{array}$ & $\begin{array}{l}\text { Platelet Retention } \\
(\%)\end{array}$ \\
\hline \multirow[t]{2}{*}{1} & 1.0 & 74.8 \\
\hline & 2.0 & 63.5 \\
\hline \multirow[t]{2}{*}{2} & $1 \cdot 7$ & $80 \cdot 1$ \\
\hline & $2 \cdot 8$ & 51.7 \\
\hline \multirow[t]{2}{*}{3} & 1.2 & 89.7 \\
\hline & $2 \cdot 8$ & 48.0 \\
\hline \multirow[t]{2}{*}{4} & 1.0 & $85 \cdot 2$ \\
\hline & $2 \cdot 0$ & $85 \cdot 2$ \\
\hline \multirow[t]{2}{*}{5} & 1.5 & $56 \cdot 3$ \\
\hline & $2 \cdot 2$ & $74 \cdot 3$ \\
\hline
\end{tabular}

However, fast flow rates decreased platelet retention in the filters. The results with four normal subjects are shown in Table III. In these experiments, $2.0 \mathrm{ml}$. blood was passed through replicate filters in 30 and seven seconds respectively. In three experiments, there was decreased retention at the higher flow rate.

TABLE III

PERCENTAGE PLATELET RETENTION AT NORMAL AND FAST FLOW RATES

\begin{tabular}{|c|c|c|}
\hline \multicolumn{3}{|c|}{ Flow Rate } \\
\hline & l./30 sec. & $2 \mathrm{ml} .17 \mathrm{sec}$ \\
\hline & $\begin{array}{l}50.0 \\
75.0 \\
75 \cdot 8 \\
54 \cdot 6\end{array}$ & $\begin{array}{l}50 \cdot 0 \\
30 \cdot 0 \\
24 \cdot 1 \\
35 \cdot 8\end{array}$ \\
\hline Mean & $63 \cdot 8$ & 35.0 \\
\hline
\end{tabular}

THE EFFECT OF HAEMATOCRIT ON PLATELET RETENTION In 33 normal subjects, no correlation was found be- $\sigma$ tween the haematocrit values of the blood, which $N$ ranged from $38 \%$ to $48 \%$, and the percentage platelet N retention.

In five patients with iron-deficiency anaemia who were not suffering from haemorrhagic disorders, the haematocrit values ranged from $27 \%$ to $32 \% \stackrel{\rho}{\rightarrow}$ (mean $30 \%$ ) but in all the percentage platelet reten- 0 tion was normal, results ranging from $49 \%$ to $79.5 \%$ (mean $71.5 \%$ ).

In five patients with polycythaemia vera, the haematocrit value ranged from $51 \%$ to $77 \%$ (mean 
$60 \%$ but in all the percentage platelet retention was normal, results ranging from $31.8 \%$ to $79.9 \%$ (mean $66 \cdot 2 \%$ ).

To study the effect of haematocrit in more detail, normal blood was mixed in the syringe with heparinized plasma from the same donor obtained by a previous venepuncture before being passed through the filter. A number of syringes, each containing a different volume of plasma, were connected in turn to the needle in the vein, and the blood samples, after mixing, were passed through separate filters. In this way, the same blood sample could be tested over a range of haematocrit values. The concentration of heparin in the heparinized blood from which the plasma was obtained was $30 \mu \mathrm{g} . / \mathrm{ml}$. The blood of four normal subjects was tested in this manner at each of four different haematocrit values. Despite considerable variation between the individual results of each set of samples from a particular donor, there was no evidence that varying the haematocrit altered the percentage platelet retention. The mean percentage platelet retention in the haematocrit range $20 \%$ to $30 \%$ was $45.4 \%$, in the range $30 \%$ to $40 \%$ it was $46.7 \%$, and in the range $40 \%$ to $50 \%$ it was also $46.7 \%$.

EFFECT OF DILUTION OF THE BLOOD Blood was diluted with varying quantities of $0.85 \%$ saline, using the multiple syringe technique to collect volumes of blood into different volumes of saline. Table IV records the results of tests in six normal donors; the degree of dilution is indicated by the change in haematocrit of the blood sample, the first result in each series referring to the percentage platelet retention using undiluted blood. In subject A, platelet retention became abnormal when the haematocrit was reduced from $45 \%$ to $25 \%$; in subject $D$, reduction of the haematocrit to $33 \%$ from $43 \%$ caused abnormal platelet retention and

\section{TABLE IV}

EFFECT ON PLATELET RETENTION OF DILUTION OF BLOOD WITH SALINE

\begin{tabular}{ccc} 
Subject & $\begin{array}{l}\text { Percentage } \\
\text { Platelet } \\
\text { Retention }\end{array}$ & $\begin{array}{c}\text { Haematocrit } \\
(\%)\end{array}$ \\
\hline A & $40 \cdot 8$ & 45 \\
& $48 \cdot 9$ & 36 \\
B & $11 \cdot 3$ & 25 \\
& $69 \cdot 4$ & 39 \\
C & $50 \cdot 0$ & 24 \\
& $67 \cdot 8$ & 39 \\
D & $54 \cdot 6$ & 26 \\
& $73 \cdot 2$ & 43 \\
E & $10 \cdot 7$ & 33 \\
& $80 \cdot 4$ & 43 \\
F & $63 \cdot 0$ & 31 \\
& $49 \cdot 7$ & 44 \\
& $28 \cdot 1$ & 32
\end{tabular}

the same effect was produced in subject $F$, when the haematocrit was reduced from $44 \%$ to $32 \%$. The results indicate that in some instances dilution of blood with saline before passage through the filter may considerably reduce platelet retention.

EFFECT OF CITRATE Blood was withdrawn from a normal subject and a portion immediately passed through the filter, as described above, to measure the percentage platelet retention. A portion of the remaining blood in the syringe was mixed with $1 / 10$ th volume of $3.8 \%$ sodium citrate and the citrated blood passed through a second filter. A further portion was mixed with $1 / 10$ th volume of $0.85 \%$ saline and passed through a third filter. Platelet counts were performed on the citrated and saline-diluted samples before and after passage through the filters and the percentage platelet retention of the citrated and saline-diluted bloods were compared were that of the native blood samples. In three tests on different donors, percentage platelet retention in native blood was $35.3 \%, 64.5 \%$, and $57.0 \%$; in the saline-diluted blood, $14.5 \%$, $32.8 \%$, and $25.0 \%$, but in the citrated blood it was $1.0 \%, 0.0 \%$, and $5.3 \%$ respectively. The mean values were $52.3 \%$ for native blood, $24.1 \%$ for saline-diluted blood, but only $2 \cdot 1 \%$ for citrated blood.

EFFECT OF TEMPERATURE Nine experiments were performed on duplicate normal blood samples, one of each pair being passed through a filter unit at room temperature, the other through a unit jacketed in ice water. The results (Table V) are difficult to interpret because of the known variation in replicate tests described above. However, with a single exception, platelet retention in the cold filter was less than in the other. In one test platelet retention was $67.6 \%$ in the filter at room temperature and only $3.4 \%$ in the cold filter. The mean value was $64.6 \%$ using the filter at room temperature and $44.7 \%$ with the cold filter.

TABLE V

EFFECT OF TEMPERATURE ON PLATELET RETENTION Percentage Platelet Retention

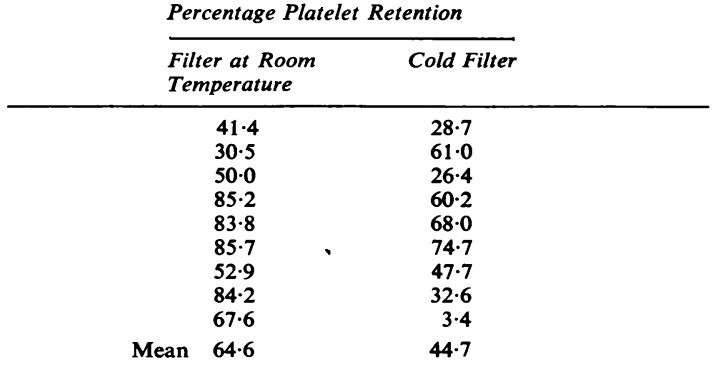


EFFECT OF ADENOSINE Adenosine at a final concentration in blood of $10^{-3} \mathrm{M}$ almost completely prevented platelet retention in the filters. In five experiments on normal subjects, $5 \mathrm{ml}$. of blood was drawn into a syringe containing adenosine in a volume of $0.2 \mathrm{ml}$. The percentage platelet retention was zero in four experiments and $9.1 \%$ in the fifth. In control experiments without the addition of adenosine, all blood samples showed normal platelet retention.

EFFECT OF SILICONIZED BEADS In five tests with normal blood, platelet retention was estimated in filter units containing siliconized glass beads (Table VI). In three experiments platelet retention was not significantly altered; in two experiments, siliconized beads caused less platelet retention than normal, but the mean differences were not striking.

TABLE VI

PERCENTAGE PLATELET RETENTION WITH SILICONIZED GLASS BEADS COMPARED WITH UNTREATED BEADS

\begin{tabular}{cc} 
Siliconized Beads & Control Beads \\
\hline $76 \cdot 7$ & $70 \cdot 3$ \\
$40 \cdot 6$ & $39 \cdot 8$ \\
$19 \cdot 7$ & 37.0 \\
$21 \cdot 6$ & $30 \cdot 2$ \\
47.8 & 67.0 \\
Mean 41.3 & 48.9
\end{tabular}

EFFECT OF HEPARIN Percentage platelet retention was estimated in patients before and after the administration of heparin (Table VII). Patients 1 to 5

TABLE VII

EFFECT OF HEPARIN ON PLATELET RETENTION

\begin{tabular}{|c|c|c|}
\hline \multirow[b]{2}{*}{ Patient } & \multicolumn{2}{|c|}{ Percentage Platelet Retention } \\
\hline & $\begin{array}{l}\text { Before Heparin } \\
\text { Therapy }\end{array}$ & $\begin{array}{l}\text { During Heparin } \\
\text { Therapy }\end{array}$ \\
\hline $\begin{array}{r}1 \\
2 \\
3 \\
4 \\
5 \\
6 \\
7 \\
8 \\
9 \\
10\end{array}$ & $\begin{array}{l}47 \cdot 2 \\
32 \cdot 8 \\
42 \cdot 3 \\
78 \cdot 1 \\
63 \cdot 3 \\
61 \cdot 4 \\
76 \cdot 7 \\
72 \cdot 4 \\
40.8 \\
89 \cdot 6\end{array}$ & $\begin{array}{l}36 \cdot 7 \\
40 \cdot 1 \\
66 \cdot 8 \\
60 \cdot 1 \\
46 \cdot 1 \\
83 \cdot 0 \\
66 \cdot 8 \\
69 \cdot 1 \\
37 \cdot 2 \\
85 \cdot 0\end{array}$ \\
\hline Mean & $60 \cdot 5$ & $59 \cdot 1$ \\
\hline
\end{tabular}

received heparin by continuous intravenous infusion of 30,000 N.I.H. units $(300 \mathrm{mg}$.) over 24 hours, whereas patients 6 to 10 were given a single intravenous injection of 5,000 to 10,000 N.I.H. units of heparin, samples for testing being collected just before and five minutes after the injection. In no instance did heparin produce abnormal platelet retention. Before giving heparin the mean platelet retention was $60.5 \%$ and $59.1 \%$ during heparin therapy. In six patients the concentration of heparin in the blood, measured by a protamine titration technique, ranged from 5 to $30 \mu \mathrm{g} . / \mathrm{ml}$. (mean $14 \mu \mathrm{g} . / \mathrm{ml}$.).

EFFECT OF ORAL ANTICOAGULANTS The test was carried out on five patients receiving phenylindanedione (Dindevan) in whom the one-stage prothrombin time was unduly prolonged. The prothrombin times ranged from 51 to 114 seconds (normal control 14 seconds), the mean being 81 seconds. In these cases, the platelet retention ranged from $37.5 \%$ to $91.1 \%$ (mean $72.6 \%$ ). Dindevan therapy, therefore, does not affect the result of this test.

STUDIES IN URAEMIA The test was performed on blood samples from 40 consecutive patients who had blood urea concentrations persistently exceeding $100 \mathrm{mg} . \%$. Twenty-two samples showed decreased platelet retention in the glass bead filter, values ranging from $3.1 \%$ to $28.3 \%$ (mean $15.8 \%$ ). In 18 samples, normal values were obtained, ranging from $30 \cdot 1 \%$ to $73 \cdot 7 \%$ (mean $48 \cdot 1 \%$ ).

PLASMA ADENOSINE DIPHOSPHATE (A.D.P.) ACTIVITY No A.D.P. activity could be demonstrated in native plasma prepared from normal blood which had passed through the filter unit. Of the neutralized perchloric acid extract of such plasma, $0.3 \mathrm{ml}$. did not alter the optical density produced by $2.7 \mathrm{ml}$. of citrated platelet-rich plasma when the mixture was vigorously agitated. In contrast, the extract from blood to which A.D.P. had been added before passage through the filter, caused platelet aggregation in the indicator system.

\section{DISCUSSION}

There are several possible reasons for the wide range of results obtained with the platelet retention test on samples of blood from normal individuals. These include errors inherent in visual platelet counting, variation in either the packing of the glass bead filters, or the rate of blood flow through the filter units, variable haematocrits and blood viscosities in normal individuals as well as differences in platelet reactivity. The variability noted with replicate testing (Fig. 2), when blood from the same syringe was passed through two filter units, suggests that errors in platelet counting or differences in filter units are the most likely explanation for the wide range of normal results. Minor differences in blood flow rates appear unimportant (Table II) 
although platelet retention is decreased at very fast flow rates (Table III).

The haematocrit value of the blood within the test range of $20 \%$ to $77 \%$ does not appear to influence the results. There was no correlation between haematocrit and platelet retention in normal individuals; platelet retention was normal in patients with iron-deficiency anaemia and with polycythaemia vera, and dilution of blood with the donor's own heparinized plasma did not affect the result. These observations differ from those of Hellem (1960), who found a correlation between platelet retention and haematocrit in a test system using citrated blood and a glass bead column. However, our results agree with those of Salzman and Neri (1966) who found no correlation between platelet retention and haematocrit in uraemic blood.

Dilution of blood with saline sometimes reduced platelet retention in the filter units. Since the reduction is not primarily related to haematocrit, the effect of saline dilution is probably due to a decrease in blood viscosity.

Despite the rather poor replicability of the results recorded in Fig. 2, no sample of normal blood has shown a platelet retention value below $30 \%$, even on repeated testing (Table I). The observation that 22 of 40 patients who had persistently raised blood urea values gave a result below $30 \%$ indicates that the test may have clinical value.

When platelet-rich plasma is vigorously stirred after the addition of adenosine diphosphate, a rapid and marked clumping of platelets occurs (Born, 1962). Platelet aggregation may be initiated by a variety of other substances, including thrombin, adrenaline, noradrenaline, and 5-hydroxytryptamine (Mitchell and Sharp, 1964). It is possible that platelet retention in the glass bead filter test could be the result of aggregation with trapping of the aggregates; indeed, Salzman (1963a, b) observed platelet clumps in a column of glass beads through which native blood had been passed, and O'Brien and Heywood (1966) found that the addition of glass beads to stirred heparinized plasma will produce platelet aggregation. The passage of blood through the filter could cause sufficient mechanical cell damage for A.D.P. release and the extreme turbulence would give rise to many platelet collisions, providing the conditions necessary for aggregation to occur. Some of the present findings provide indirect evidence for such a mechanism of platelet retention. Thus platelet aggregation induced by A.D.P. requires the presence of calcium ions and the reaction is inhibited by adenosine (Born, 1962). Platelet retention in the glass bead filter was inhibited by both citrate and adenosine. Furthermore, platelet aggregation induced by A.D.P. is temperature dependent, being less at low temperatures (O'Brien, 1962), and the present findings with cold filters suggest that cooling the blood also reduces platelet retention. Therapeutic doses of heparin or phenylindanedione do not affect platelet retention in the filter or aggregation of platelet in plasma induced by adenosine diphosphate.

We failed to demonstrate A.D.P. in plasma obtained from blood issuing from the filters. Although it is possible that any A.D.P. liberated was degraded before perchloric acid precipitation, this appears unlikely since our manipulations were carried out rapidly at $4^{\circ} \mathrm{C}$. Furthermore, small amounts of A.D.P. added to blood before its passage through the filter could be demonstrated in the neutralized perchloric acid extracts. Hampton and Mitchell (1966) indicated that A.D.P. could be adsorbed onto the surface of platelets or onto uncoated glass and such a mechanism could account for our failure to demonstrate adenosine diphosphate.

Tests for platelet aggregation induced by A.D.P. should give similar results to those of platelet retention in glass bead filter units if A.D.P.-induced aggregation is the cause of the latter. Salzman and Neri (1966) described normal platelet aggregation in uraemic blood; however, decreased aggregation has been reported by Castaldi, Rozenberg, and Stewart (1966) when bleeding was present. We have performed both platelet retention and aggregation tests on blood samples from 17 patients with blood urea concentrations greater than $100 \mathrm{mg} . \%$. There was correlation between the two results in nine cases; in seven, the aggregation test was abnormal while platelet retention was normal, and in one, the position was reversed. It appears that the platelet aggregation test is more sensitive than the glass bead filter test as an index of the platelet disorder in uraemia, but the results do not disprove the suggestion that the mechanism of both tests is similar. The observation that platelet aggregation is normal in von Willebrand's disease, whereas the glass bead filter test produces an abnormal result is more difficult to interpret. Again, the difference may be simply one of sensitivity, as platelets from patients with von Willebrand's disease are reported to react abnormally to low concentrations of A.D.P. (Vainer and Caen, 1964).

Normal platelets adhere readily to glass (Wright, 1941), possibly due to the presence of exogeneous A.D.P. (Jones, 1966). Platelet adhesion to the glass beads could account for retention of platelets in the filter; however, this appears unlikely since comparable retention was obtained using siliconized and untreated glass beads, indicating that the result is largely independent of the state of the bead surface. The evidence favours platelet aggregation as the 
more important factor in the mechanism of platelet retention in this type of filter unit.

\section{REFERENCES}

Born, G. V. R. (1962). Nature (Lond.), 194, 927.

Castaldi, P. A., Rozenberg, M. C., and Stewart, J. H. (1966). Lancet, 2,66 .

Hampton, J. R., and Mitchell, J. R. A. (1966). Brit med. J., 1, 1074. Hellem, A. J. (1960). Scand. J. clin. Lab. Invest., 12, suppl. 51.
Jones, B. M. (1966). Nature (Lond). 212, 362.

Mitchell, J. R. A., and Sharp, A. A. (1964). Brit. J. Haemat., 10, 78. O'Brien, J. R. (1961). J. clin. Path., 14, 140. (1962). Ibid., 15, 452.

- and Heywood, J. B. (1966). Ibid., 19, 148

Salzinan, E. W. (1963a). J. Lab. clin. Med., 62, 724.

(1963b). Transfusion (Philad.), 3, 274.

, and Neri, L. L. (1966). Thrombos. Diathes. haemorrh. (Stuttg.), $15,84$.

Strauss, H. S., and Bloom, G. E. (1965). New Engl. J. Med., 273, 171.

Vainer, H., and Caen, J. P. (1964). J. clin. Path., 17, 191.

Wright, H. P. (1941). J. Path. Bact., 53, 255. 